\title{
EL CONSEJO DE FAMILIA
}

\section{RESUMEN}

Benjamín Aguilar Llanos*

Una de las instituciones del Derecho de Familia que menos presencia tiene en nuestros tribunales, es precisamente el Consejo de Familia; las razones que se dan para su poca aplicación, son varias, desde la aparente desaparición de la familia compuesta y extendida, la forma tan reglamentarista en que ha sido regulada la institución, asi como su visión patrimonialista de la misma; sin embargo, la institución fue creada para cumplir un rol importante dentro del contexto del grupo familiar, y a ello debemos apuntar.

El presente trabajo, pretende desarrollar el conocimiento de la institución, sus funciones y los objetivos que persigue, todo ello dentro de la regulación que nos trae el Código Civil, y sin perjuicio de formular las críticas y recomendaciones para lograr la eficaciadela Institución.

Palabris clave: Derecho de Familia, Consejo de Familia

\section{THE FAMILY COUNCIL}

\begin{abstract}
One of the institutions of the Family Law with less presence in our courts, is precisely the Council of family; there are several reasons given for the little application of it, since the apparent demise of the compound and extended family, the regime way in which the institution has been regulated, as well as its patrimonial vision; however, the institution was created to fulfill an important role within the context of the family, and we should aim to it.

This work aims to develop the knowledge of the institution, its functions and objectives, all within the regulation which brings the Civil Code, and without making criticisms and recommendations forensuring the effectiveness of the institution.
\end{abstract}

Key words: Family Law, Family Council

\footnotetext{
* Abogado, egresado de la Pontificia Unviversidad Católica del Perá, conciliador extrajudicial y árbitro, con estudios de Maestria. Docente de la Facultad de Derecho y en la Maestría en Derecho Civil con mención en Familia de la INDTF. Ha sido Presidente de la Comisión de Familia del Colegio de Abogados de Lima e integrante de ta Comision de Sucesiones. Expositor nacional e internacional. Autor de varios libros: "Instituto Jurídico de la Familia", "La Familia en el Código Civil Peruano, "Derechu deSucesiones", entreatros.

Recepción:01-08-2012

Aceptación: 28 -08-2012
} 


\section{INTRODUCCIÓN}

El Consejo de Familia debería ser una institución con una intervención rápida y oportuna en la solución de los diferentes problemas familiares que se presentan en el mundo de hoy; y, a guisa de ejemplo mencionamos, problemas como los conflictos de pareja, que penosamente vemos luego desfilar a través de la separación legal o divorcio, los conflictos que se dan entre los padres respecto de sus hijos, y que luego vemos como los juzgados de familia se abarrotan de trámites de tenencia, régimen de visitas, o suspensión de patria potestad. El Consejo de Familia, bien concebido y con un expeditivo funcionamiento, evitaría que estos problemas alcancen las puertas del Poder Judicial, y se resuelvan dentro del entorno familiar; sin embargo, hoy observamos que esta institución es poco menos que inoperativa, por las limitaciones que se dan y que provienen de la misma regulación, que incluso ha llevado a cierto sector de la doctrina a tomar postura respecto a su desaparición e incluso legislaciones como la brasileña y ecuatoriana ya no la regulan; sin embargo, seguimos pensando como el ilustre peruano del siglo XIX, don Manuel Lorenzo Vidaurre y Encalada, que el consejo de familia está liamada a velar por los intereses de los niños y adolescentes e interdictos, pero también debe ser la institución que termine resolviendo los diversos problemas que se presentan dentro del entomo del medio familiar.

En 1834, don Manuel Lorenzo Vidaurre y Encalada, en su proyecto de Código Civil decía sobre el Consejo de Familia "A primera vista se reconocen los útiles resultados, se evitarian muchos pleitos y causas escandalosas, sería muy fácil la reconciliación entre el marido y la mujer, y entre éstos y los hijos. Se uniría la justicia con la equidad y el interés personal, por lo general ominoso, aprovecharía en tales circunstancias, no les sería indiferente un proceso en que se comprometa el honor de la familia"; sobre el particular, el ilustre jurista tenía un concepto amplio de la institución, refiriéndola a la familia amplia, a quien se le daba atribuciones que tengan que ver con todo lo concerniente al grupo familiar, y no sólo el cuidado de los intereses de los incapaces, como sucede en el presente, sino mas bien, una suerte de alegres componedores de problemas familiares, evitando que estos conflictos salgan de la esfera doméstica para confrontarlo en la vía judicial, volviendo el problema en casi insoluble. Pues bien, este noble deseo de Vidaurre no fue recogido ni por el código civil de 1852, ni de 1936, ni por el de 1984.

En el derecho moderno, algunas legislaciones han adoptado que el cuidado de los incapaces, cuyos padres no se encuentran al lado de ellos, se 
entregue a los familiares de éstos, quienes reunidos toman el nombre de Consejo de Familia; otras legislaciones prefieren que sea el Estado el encargado de vigilar a los incapaces, y otros prefieren una suerte de combinación con presencia de la familia y del Estado

Generalmente se admiten tres sistemas de guardaduría de incapaces: el Latino, con una presencia gravitante de la familia (Francia y Bélgica); el Germano, con una presencia marcada del Estado (Alemania, Suiza), y el Mixto, con presencia de la familia y del Estado (Perú, Chile, Argentina, entre otros). A la par de ello, también habría que considerar que existen un buen número de legislaciones que no regulan al consejo de familia, y más bien las funciones propias de esta institución, son asumidas por un tribunal de tutelas, o por un juez tutelar, y ello lo vemos por ejemplo en América Latina, er países como Ecuador, Paraguay, Uruguay y Brasil que no comprenden dentro de sus legislaciones, al Consejo de Familia.

Se discute si el Consejo de Familia es un tribunal de derecho; por ejemplo, en España, el Consejo no tiene carácter de tribunal de derecho pues no está presidido nc "un juez, a la par de no habérsele concedido atribuciones ofjiciajes ni ejecutivas, como sí lo tiene el derecho francés y el peruano; ahora bien, hay un sector importante de legislaciones que consideran al Consejo, una suerte de tribunal privado, en donde llegan situaciones por resolver, y que ta: tribunal está presidido por un juez, sea el de Familia, si se trata de ventilar asuntos de niños o adolescentes, o de juez de paz letrado, si se trata de ver situaciones en las que está inmerso un mayor de edad incapaz; ejemplo de ello lo tenemos en el caso peruano.

En nuestro país, el Consejo de Familia siempre ha figurado en el Código Civil, como una especie de asamblea de parientes reunidos a fin de cuidar y garantizar los intereses de los menores de edad, cuyos padres no ejercían patria potestad, o de los mayores incapaces, e incluso la normatividad que regula la institución ha sido detallista, y a veces, repetitiva e innecesaria, dándole al Consejo pattas para su formación y ejecución que no han sido expeditivas, sino todo lo contrario, por lo cual el Consejo poco o nada ha tenido aceptación.

Sin embargo, una de las principales causas por las que el pueblo, mayoritariamente no lo ha hecho suyo, no lo ha incorporado, es por la grave crisis que sufre la familia, en donde el individualismo que ha llevado al 
egoísmo, ha convertido a la institución en casi siempre inoperante. En el presente tenemos una familia básicamente nuclear, en donde aparte de los padres y los hijos, los otros parientes terminan siendo extraños a esa familia, y es con estos parientes con los que precisamente se va a formar el Consejo, lo que da como resultado que casi o nunca se forme.

Por otro lado, la regulación de las instituciones de amparo del incapaz, como son la tutela, curatela, y el Consejo de Familia tienen un corte básicamente patrimonialista, lo que torna a la institución en estudio, poco utilizada, pues son reducidos en cuanto a número, los incapaces con patrimonio propio, y en tal circunstancia pierde su razón de ser la mencionada institución, en cuanto que básicamente se dirige a cuidar los intereses económicos de estos incapaces; sin embargo, ello no debe ser así, por cuanto la institución debe existir, en tanto existan incapaces a quienes se debe cuidar en cuanto a su persona y sus bienes, controlando y vigilando los abusos en que podría incurrir quienes, precisamente son los llamados a cuidarlo, esto es los tutores y curadores, y por otro lado, un fin mucho más noble la encontramos en el fortalecimiento de la familia, aún cuando somos realistas sobre el particular, en tanto que la inoperatividad de la institución se debe precisamente al resquebrajamiento y crisis de la familia.

\section{CONCEPTO DEL CONSEJO DE FAMILIA}

El jurista español Clemente de Diego, la describe como una reunión de personas nombradas por el padre o por la madre o en su defecto llamadas por ley, que provee al nombramiento de tutor o protutor, delibera sobre la exclusión o remoción, dicta medidas necesarias para atender a las personas y bienes de los menores o incapacitados, vigila la administración del tutor, autoriza ciertos actos de disposición y examina y censura la rendición de cuentas del tutor; mientras que Calixto Valverde y Valverde, refiere que es un cuerpo de potestad ejecutiva, compuesta de cinco o más personas designadas por el padre o la madre, y en su defecto llamado por ley, para procurar el exacto cumplimiento de los deberes del tutor, resolver los asuntos de la tutela de más importancia y ejercer la alta inspección sobre la misma.

Por nuestro lado, preferimos referimos al Consejo como la reunión de parientes del incapaz para velar por sus intereses, en cuanto a su persona y patrimonio, y en esa medida es fiscalizador de los guardadores, sean estos tutores, curadores e incluso padres en el ejercicio de la patria potestad. Pero 
este concepto de la institución, no nos impide tomar posición respecto a que, si bien es cierto el Consejo está formado generalmente por familiares del incapaz, también lo es que el Consejo puede estar integrado por personas ajenas al incapaz, cuando han sido convocados testamentariamente, por el padre o la madre del incapaz. Esta asamblea de parientes es presidida por un juez, quien convoca, dirige los debates, y preside las votaciones.

La nueva legislación del niño y adolescente, ha concedido participación activa al adolescente en las reuniones del consejo, habiéndole dado voz y voto, así como ha contemplado la participación igualmente del niño, quien será escuchado con las restricciones propias de su edad.

\section{FORMACIÓN E INSTALACIÓN DEL CONSEJO DE FAMILIA}

Recordemos que se trata de una instizución temporal, en tanto que se reúne para una determinada gestión, a la par que su composición es variable, porque los miembros pueden variar de una reunión a otra, pues bien, el artículo 101 del Código de los Niños y Adolescentes, refiere que habrá Consejo de Familia para velar por la persona e intereses del niño o del adolescentie que no tenga padre ni madre, o que se encuentre incapacitado conforme lo dispone el artículo 619 del Código Civil; esta última referencia alude a los incapaces mayores de edad que no tengan padre ni madre. Creemos que la norma crea confusión, pues pueden existir niños o adolescentes con padres pero que no están en el ejercicio de la patria potestad, caso en el cual obviamente entra a tallar el Consejo, por' lo tanto, la norma debió referirse a los niños y ađolescentes cuyos padres no ejercen patria potestad; sin embargo, el mismo artículo 619 refiere que también habrá consejo aunque viva el padre o la madre en los casos que señala el código, y en efecto los artículos $341,426,427,428,433$ y 460 del Código Civil prevé los casos en que en estos supuestos, existiendo padre o madre, o ambos, rige el Consejo de Familia. Veamos por separado los casos en que se forma el Consejo.

\section{CONSEJO DE FAMILIA PARA NIÑOS Y ADOLESCENTES QUE NO TENGAN NI PADRE NI MADRE}

Tal como ya lo hemos dejado aclarado debió precisarse al aludir a los padres, que éstos no ejerzan patria potestad, situación que abarca todos los posibles casos en los que se comprende: muerte de los padres, suspensión o extinción de la patria potestad; pues bien, en estos casos es necesario que la 
patria potestad sea suplida por la figura de la tutela, y si ésta no ha sido convocada testamentariamente por los padres y no hay ascendientes, será el Consejo de Familia el que designe al tutor dativo; e incluso cuando hay designación de tutor por parte de los padres, o del tutor legítimo, el Consejo de Familia deberá vigilar la labor de este guardador.

Cuando los padres no están al lado de sus hijos, el tutor debe velar por la persona y bienes del niño o adolescente, y quien fiscaliza esta labor es precisamente el Consejo de Familia, con amplias facultades no sólo para vigilarlo sino también para promover su remoción, o removerlo si se trata del tutor dativo. Aquíel Consejo es presidido por el Juez de Familia.

\section{CONSEJO DE FAMILIA PARA LOS MAYORES DE EDAD INCAPACES QUE NO TENGAN PADRE NI MADRE}

Estos incapaces están bajo el cuidado del curador quien está supervisado por el Consejo de Familia, entidad ésta que igualmente nombra al curador cuando no existen los llamados a la curatela legítima, ni la designación de los padres vía testamento o escritura pública. El supuesto es de que estos incapaces no tengan padre ni madre, pues si así fuera, son ellos los llamados a cuidar al hijo incapaz bajo la forma de la curatela legítima, y generalmente no se forma Consejo cuando los padres tienen a sus hijos bajo patria potestad, o bajo curatela, pues se parte de la presunción de que el cưidado será el más conveniente para el incapaz.

\section{CONSEJO DE FAMILIA AUNQUE VIVA EL PADRE O LA MADRE EN LOS CASOS EN QUE SEÑALA EL CÓDIGO CIVIL}

En efecto, generalmente no se forma el Consejo cuando los padres ejercen patria potestad sobre sus hijos, pues el supuesto es de que tal institución se forma generalmente para vigilar a los tutores y curadores, pero no para los padres que ejercen patria potestad o ejercen la curatela, en atención a que la proximidad del parentesco, hace presumir un desempeño adecuado y eficaz del cuidado del incapaz; sin embargo, por excepción se señalan casos en los que debe funcionar el Consejo. Veamos cuales son estos casos:

a) Padres divorciados en el que el ejercicio de la patria potestad recae en uno de ellos. En esta situación el artículo 341 del Código Civil, refiere que en cualquier tiempo el juez puede dictar a pedido del Consejo de 
Familia, las providencias que sean requeridas y que considere que son beneficiosas para los hijos.

b) Los padres no están obligados a dar garantía para asegurar la responsabilidad de la administración del patrimonio de sus hijos, salvo que el juez a pedido del Consejo de Familia, resuelva que to constituya por requerirlo el interés del hijo. El artículo 426 que establece tal potestad del Consejo, lo hace en atención a que esta asamblea de parientes tiene razonable duda sobre la gestión del padre o madre frente a la administración legal.

c) En cuanto a la rendición de cuentas periódicas respecto de la administración legal, los padres no están a obligados a ello, salvo que lo solicite el Consejo de Familia tal como lo manda el artículo 427 del Código Civil.

d) Siempre a pedido del Consejo de Familia, el juez puede dictar las medidas que considere conveniente respecto de la administración que vienen realizando los padres sobre los bienes de sus hijos. Esta disposición contenida en el artículo 428 del Código Civil, se enmarca dentro de las medidas de protección de los intereses de los infantes bajo patria potestad.

e) El padre o madre que ejerce en exclusividad patria potestad y pretende contraer matrimonio, debe solicitar la formación del Consejo de Familia, a fin de que esta entidad se pronuncie sobre la administración legal de los bienes del menor y si ha de continuar en dicha administración este padre o madre. El artículo 433 del Código Civil exige tai convocatoria y si se hace caso omiso de ello, se pierde la administración y el usufructo legal.

f) Uno de los casos de decadencia de la patria potestad, en el que se aparta al padre o madre de la administración de un determinado bien, es cuando haya conflicto u oposición de intereses entre padre e hijo, en tal circunstancia el artículo 460 del Código Civil, ordena el nombramiento de un curador especial, recayendo tal designación en el ascendiente a quien le corresponde la tutela legítima, y si no fuera posible la designación, la hará el Consejo de Familia.

Obsérvese que en todos estos casos se viene ejerciendo la patria potestad; sin embargo, el legislador contempla la existencia de determinadas situaciones, que hacen aconsejable que el Consejo de Familia funcione siempre en función de cautelar los intereses del infante. 


\section{CONSEJO PARA EL AUSENTE}

Refiere el artículo 638 del Código Civil que también se forma consejo para que ejerza sus atribuciones a favor de los ausentes; en efecto, según el artículo 50 del Código Civil, en la declaración judicial de ausencia se ordenará dar la posesión temporal de los bienes del ausente, a quienes serían sus herederos forzosos al tiempo de dictarla, y que si no hubiera persona con esa calidad, continuará respecto a los bienes del ausente, la curatela establecida en el artículo 47, referida a la curatela de bienes del desaparecido.

En el caso del desaparecido la situación es de incertidumbre; por ello, la ley faculta a que se designe un curador especial que cuide sus bienes, en tanto no se dilucide su situación jurídica, pues bien este curador especial será fiscalizado por el Consejo de Familia. En el caso del ausente, la ley da otra salida, que se traduce en entregar provisionalmente el patrimonio del ausente a los que resulten sus herederos forzosos, pero obsérvese que se trata de una ministración provisional; por ello, entendemos que aún en este caso el Consejo de Familia tiene funciones que cumplir, en cuanto que se debe fiscalizar la administración de ese patrimonio que vienen contenidas en el Código Civil, er sus artículos 51 referida al inventario de los bienes, 52 que establece la prohibición de enajenar bienes del ausente y principalmerte el artículo 55 sobre derechos y obligaciones del administrador judicial de los bienes del ausente.

\section{CONSEJO NO SE FORMA PESE A LA NO EXISTENCIA DE PADRES}

Si estamos a lo dispuesto en el artículo 101 del Código de los Niños y Adolescentes o el 619 del Código Civil, en tal supuesto debería formarse el Consejo de Familia para velar por los intereses de estos incapaces que carecen de padres expeditos; sin embargo, observamos una serie de casos en el que no existiendo padres no se forma el Consejo; sobre el particular analicemos los más importantes:

1) Niño o adolescente cuyo tutor legítimo es al mismo tiempo curador de su padre o madre (supuesto recogido en el artículo 620 del Código Civil). Sobre el particular, dirernos que el artículo 580 del Código Civil, refiere que el curador de un incapaz que tiene hijos menores será tutor de éstos; pues bien, en aplicación de ello, y sobre todo porque el padre o la madre ha caído en interdicción, y por lo tanto, se le suspende la 
patria potestad y se le nombra curador, cargo éste desempeñado por su propio padre o madre, que viene a ser abuelo del hijo del incapaz, y por lo tanto, llamado a la tutela legítima. En consecuencia, una misma persona reúne dos títulos, el de curador de su hijo y tutor de su nieto; siendo ello así, y por el cercano y directo parentesco con el niño o adolescente, el legislador no considera necesario se reúna el Consejo de Familia, pues entiende que el guardador cumplirá fielmente sus responsabilidades, salvo en los casos en que ante la presencia de padres, la ley exige formación del Consejo, y que como ya lo hemos visto son los supuestos de los artículos $426,427,428,460$, entre otros.

2) Cuando no hay un mínimo de 4 miembros para la formación del Consejo, éste no se constituye y sus funciones son asumidas por el Juez, tal como lo señala el artículo 626 en su tercer párrafo. Cree el legislador que el reducido número no es aconsejable para una conveniente deliberación y toma de acuerdos en beneficio del incapaz.

3) El artículo 630 del Código Civil nos señala otro caso, al referir que no habrá Consejo de Familia para un hijo extramatrimonial, cuando el padre o la madre lo haya prohibido en su testamento o por escritura pública. Se respeta la voluntad del padre o la madre del hijo extramatrimonial, que tiene razonables dudas del comportamiento de los familiares del hijo, y en esa medida prohíbe la instalación del Consejo. En este caso el juez asumirá las funciones del consejo oyendo a los miembros natos que hubiere.

\section{PERSONAS OBLIGADAS A SOLICITAR LA FORMACIÓN DEL CONSEJO}

El artículo 621 del Código Civil, nos señala a las personas que están obligadas bajo responsabilidad, a solicitar la formación del Consejo de Familia cuando existan hechos que hagan necesario su funcionamiento:

a) El tutor testamentario o escriturario, persona ésta que como sabemos ha sido designada por el padre o la madre del incapaz, y en su defecto por el tutor legítimo y hasta por un tercero que ha nombrado al menor su heredero olegatario.

b) Ascendiente llamado a la tutela legítima, pues bien en este caso el abuelo o abuela en pleno ejercicio de su cargo, debe solicitar la 
formación del Consejo cuando las circunstancias lo justifiquen.

c) Miembros natos del Consejo, y lo son los abuelos y abuelas, tíos y tías, hermanas y hermanos del infante o del incapaz mayor de edad.

d) El artículo 622 del Código Civil faculta igualmente al Juez de Familia o de Paz Letrado, según fuera el caso, a decretar la formación del Consejo de oficio, o a pedido del Ministerio Público o de cualquier persona

\section{CLASES Y COMPOSICIÓN DEL CONSEJO DE FAMILIA}

En nuestra legislación existen hasta tres clases de Consejo de Familia: el testamentario o escriturario, el legítimo y el dativo. Veamos la composición de cada uno de ellos.

1) Testamentario o escriturario. Refiere el artículo 623 del Código Civil, que este consejo se compone por las personas que haya designado el último de los padres que tuvo al hijo bajo su patria potestad, o su curatela, y en su defecto, por las personas designadas por el tutor legítimo, o el abuelo o abuela que haya ejercido la curatela legítima. Obsérvese que no se pone límite al número de personas por lo tanto el número es abierto, y creemos igualmente que no hay prohibición para la designación de las personas, pudiendo ser éstas parientes o no del incapaz, aún cuando de ordinario serán familiares del incapaz.

2) Legítimo. En defecto del testamentario o escriturario, la ley llama a integrar el Consejo a los parientes próximos y directos del incapaz, a quienes se les conoce como miembros natos del Consejo, esto es, abuelos y abuelas (se entiende que ninguno de ellos ejerce la tutela legítima), tíos y tías y hermanos y hermanas del incapaz; ahora bien, si hubiera menos hermanos enteros que medios hermanos, sólo asisten de éstos igual al número de aquéllos. Excepcionalmente, aumenta el número de miembros del Consejo legítimo, cuando el mayor incapaz para quien se forma Consejo tiene hijos capaces, integrando éstos el Consejo que se forma para su padre, se entiende que aquí no está comprendido el hijo que ejerce la curatela legítima de su padre. También aumenta el Consejo legítimo, a decir del artículo 624, cuando los padres no tienen la administración de los bienes de sus hijos, sexán miembros natos del Consejo que se forme; explicable la norma por cuanto, pese a que el padre o madre no tenga la administración, sigue 
teniendo legítimo interés sobre el patrimonio del hijo, y por lo tanto, debe integrar el consejo que se forme para vigilar al administrador.

3) Dativo. Se forma en dos casos: el primero, para completar el número requerido por ley para que funcione el Consejo de Familia, cuando no hay 4 miembros natos del Consejo, entonces se llama a los demás parientes consanguíneos, entre los cuales tiene preferencia el más próximo al más remoto y el de mayor edad cuando sean del mismo grado; y en segundo lugar, cuando no hay ningún miembro nato, en estecaso se llama a los sobrinos y primos hermanos del incapaz.

\section{SOLICITUD DE FORMACIÓN DEL CONSEJO}

Quien acude al Juez a solicitar la formación del Consejo, debe indicar los nombres de las personas que integrarán dicho Consejo, y si ignora los nombres, 10 manîfestará para que el aviso que se publicará en el periódico, convoque a las personas que se crean con derecho a integrarlo, precisando eso sí, el nombre del solicitante y los datos del incapaz.

Ante la solicitud, el juez ordena la publicación de un extracto de la peticiora a fin de que cualquier interesado pueda observar la inclusion 0 exclusión indebida. Si dentro de los diez dias de la publicación no se formula observación alguna, o resuelta ésta, el juez procederá a instalar formalmeñe el Consejo.

\section{PERSONAS MPEDIDASDESER MEMBROS DEL CONSEJO}

Según el artículo 632 del Código Civil y en concordancia con el articulo 515 no pueden ser miembros del Consejo los siguientes:

a) El tutor ni el curador. Por cuanto el Consejo se forma para fiscalizarios.

b) Los que están impedidos para ser tutores o curadores.

c) Las personas a quienes el padre o la madre, el abuelo o la abuela, hubiesen excluido de este cargo en su testamento o por escriturz pública. Se respeta la voluntad de estas personas que con razones que el Código no las obliga a explicitar, apartan a alguien del cargo.

d) Los hijos de la persona que por abuso de la patria potestad dé lugar a su formación; el supuesto está referido a aquel padre o madre que es apartado de la patria potestad por una inconducta cometica en 
agravio de su hijo, pues bien, los hermanos capaces de éste no integrarán el Consejo, pues no tendrían la suficiente imparcialidad para ejercer el cargo, pese a que como se ha visto son miembros natos del Consejo.

e) Los padres, en caso que el Consejo se forme en vida de ellos, pues su formación se hace precisamente para fiscalizarlos, salvo el caso de los padres que no tienen la administración de los bienes de sus hijos, en el que si integran el Consejo precisamente para vigilar al administrador de esos bienes.

\section{INSTALACIÓN Y SESIONES DELCONSEJO DE FAMILIA}

Instalado el Consejo, sus miembros serán citados por esquela cada vez que sea necesario, debiendo precisarse que cl cargo de miembro del Consejo es gratuito e inexcusable (obligatorio), y debe desempeñarse personalmente, salvo que el juez autorice por causa justificada la representación mediante apođarado, éste no puede representar a más de un miembro del Consejo.

El Juez convocará al Consejo a solicitud del tutor, del curador o de cualquiera de sus miembros y cada vez que a su juicio, el interés del infante o del incapaz lo exija. Ante la citación efectuada, todos y cada uno de los miembros del organismo están en la obligación de concurrir, salvo que medie causa atendible; ante la inasistencia injustificada el juez impondrá una multa equivalente a no más del $20 \%$ del sueldo mínimo vital.

EI Consejo no puede adoptar resolución sin que estén presentes en la deliberación y votación por lo menos tres de sus miembros además del Juez, número éste que vendría a ser el quórum y sin que haya conformidad de votos entre la mayoría de los asistentes. El Juez que preside el Consejo solamente vota en caso de empate.

Ningún miembro del Consejo asistirá a su reunión ni emitirá voto cuando se trate de asuntos en que tengan interés él, sus descendientes, ascendientes o cónyuge, pero podrá ser oído si el Consejo lo cree pertinente. En cuanto a los tutores y curadores tienen la obligación de asistir cuando sean citados, o cuando cllos hayan promovido la reunión, pero en ningún caso pueden votar.

Según el artículo 102 del Código de los Niños y Adolescentes, el adolescente participará en las reuniones del Consejo de Familia con derecho a 
voz y voto, recordemos que se considera adolescente a partir de los 12 años, y en cuanto al niño será escuchado con las restricciones propias de su edad.

\section{ACUERDOS DEL CONSEJO DE FAMILIA}

Para lo toma de acuerdos se entiende que debe haber ur debate, que significa cambio de pareceres, opiniones, y todo ello bajo la dirección del juez; sobre el particular y según el artículo 639 del Código Civil, el Juez de Familia preside el Consejo que se forme para supervigilar al tutor o en su caso a los padres, y el Juez de Paz Letrado cuando se forma para incapaces mayores de edad.

Agotado el debate cada cuestión debe votarse por separado.

Tal como ya se ha señalado, el Consejo no puede adoptar resolución sin que estén presentes en la deliberación y votación por lo menos tres de sus miembros, además del Juez que preside y sin que haya conformidad de votos entre la mayoría de los asistentes. El Juez sólo vota en caso de empate; ahora bien, la votación, entendemos, debe ser abierta y no secreta y ello para posibilitar nue el consejero que no comulgue con los acuerdos impugne tales acuerdos.

De las sesiones del Consejo se extenderá acta en el libro de consejos de familia del juzgado, y en un libro especial que conservará el pariente más próximo, tal como lo prevé el artículo 652 del Código Civil.

\section{FACULTADES DEL CONSEJO}

Las funciones están señaladas en relación directa con la protección que se debe al interés de los incapaces para quienes se forma; ahora bien, el artículo 647 menciona las más importantes, sin embargo otras funciones no contempladas en dicho dispositivo encontramos tanto en otros libros del Código Civil, corno en el Código Procesal Civil. Analicemos cada una de estas funciones:

1) Nombrar tutores dativos o curadores dativos generales y especiales conforme a este código, se refiere a lo dispuesto en los artículos 573 que estatuye que ante la falta de curador legítimo y de curador testamentario o escriturario, la curatela corresponde a la persona que designe el Consejo de Familia, y en cuanto al artículo 508, se concede al 
Consejo designar tutor dativo ante la ausencia de tutor testamentario - escriturario y de tutor legítimo. $Y$ en cuanto a los curadores especiales, por ejemplo la que contempla el artículo 460 del Código Civil ante oposición de intereses entre padre e hijos.

2) Admitir o no la excusa o la renuncia de los tutores y curadores dativos que nombre. Como sabemos, la facultad de designar tutores $y$ curadores dativos es del Consejo, y en tal mérito será el Consejo que se pronuncie sobre la excusa que propongan los convocados a esta guardaduría, así como la de aceptar la renuncia, en los casos en que ésta proceda, como por ejemplo el caso del artículo 552 que faculta al tutor dativo que haya desempeñado el cargo seis años puede renunciarlo, o si tratándose del curador de un mayor incapaz, no siendo su cónyuge, ascendiente o descendiente será relevado si renuncia al cargo después de 4 años.

3) Declarar la incapacidad de los tutores y curadores dativos que nombre y removerlos a su juicio. Sobre el particular, debemos señalar que se autoriza al Consejo para que sin mayor explicación pueda remover a los tutores dativos, en tal mérito consideramos innecesaria la norma contenida en el artículo 509 referida a que el tutor dativo será ratificado cada dos años por el Consejo de Familia, y lo es por cuanto a su discreción, el Consejo puede remover al tutor dativo en el momento que crea pertinente.

4) Provocar la remoción judicial de los tutores y curadores legítimos de los testamentarios o escriturarios y de los nombrados por el Juez. Cuando uno de estos tutores incurre en faltas contra el incapaz, o su gestión está siendo deficiente, o han incurrido en alguno de los impedimentos y no renuncian al cargo, entonces será el Consejo el que deba promover su remoción, lo que significa una demanda judicial contra el tutor o curador, a fin de que el juez se pronuncie sobre la remoción solicitada, de conformidad con el artículo 554 del Código Civil.

5) Decidir en vista del inventario, la parte de rentas o productos que deberá invertirse en los alimentos del menor o del incapaz en su caso, y en la administración de sus bienes si los padres no la hubieran fijado. Recordemos que uno de los pasos previos para asumir el cargo de 
tutor o curador es el inventario judicial de los bienes del incapaz; pues bien, realizado el inventario la ley le señala al Consejo, como ente que decidirá qué rentas serán utilizadas por el guardador para destinarlos a los alimentos del pupilo o curado, salvo que el padre o madre, hubiera fijado con precisión al detallar sobre la administración del patrimonio del incapaz.

6) Aceptar la donación, la herencia, o el legado sujeto a cargas dejado al menor, o en su caso al incapaz. El incapaz no puede aceptar herencia ni legados, ni donaciones por sí mismo, sino que tiene que hacerlo a través de su representante legal; sin embargo, éste representante, trátese del padre que ejerce patria potestad, o el futor o el curador requiere para aceptar herencia o legados con carga, la autorización judicial respectiva, concedida previa opinión del Consejo de Familia, tal como lo mandan los artículos 448 inciso 9 y 532 del Código Civil; en tal mérito, importante resulta la participación del Consejo quien puede repudiar o autorizar esta liberalidad, dependiendo del interés del incapaz a quien tiene que cuidar y proteger.

7) Autorizar al tutor o curador a contratar bajo su responsabilidad uno o más administradores especiales, cuando ello sea absolutamente necesario y lo apruebe el Juez. Sobre el particular debemos señalar que el tutor o curador debe ejercer el cargo personalmente, no pudiendo delegarlo en otra persona; sin embargo, ello no es óbice para que si los intereses del incapaz lo demandan, contrate a uno o más administradores, que lo ayuden a la administración eficiente de los intereses del guardado. Ahora bien, toca al Consejo prestar su consentimiento para esta contratación, sólo en el caso que sea indispensable y no resulte gravoso para los intereses del incapaz.

8) Determinar la suma desde la cual comienza para el tutor o curador, según el caso, la obligación de colocar el sobrante de las rentas o productos del menor o incapaz. En efecto, el tutor o curador no debe manejar el dinero del incapaz, sino sóto en lo indispensable para la alimentación, educación o curación, según sea el caso, y cualquier otra suma debe ser depositada en instituciones bancarias tal como lo ordena el artículo 521 del Código Civil; en tal mérito, toca al Consejo de Familia pronunciarse cuando el tutor o curador se encuentre en duda respecto del dinero del incapaz, sobre el manejo del mismo o la 
existencia de la obligación de depositarlo en entidad crediticia.

9) Indicar los bienes que deben ser vendidos en caso de necesidad o por causa de utilidad manifiesta. Sobre el particular, hay que señalar que para la disposición de los bienes del incapaz, trátese de los padres, o del tutor o curador, necesariamente requieren autorización judicial tal como lo ordenan los artículos 447,531 y 577 del Código Civil, pues bien, el legislador se pone en el caso de que el incapaz sea titular no sólo de un bien, sino de varios bienes, en tal circunstancia y con la autorización judicial se procederá a la venta del bien, recayendo en el Consejo la elección del bien, siempre dentro de lo que más convenga al incapaz.

10) Ejercer las demás atribuciones que le conceden este Código y el de Procedimientos Civiles (se entiende el Código Civil y el Código Procesal Civil); pues bien, en cuanto al Código Civil a parte de los casos ya comentados, también se requiere la intervención del Consejo de Familia para los siguientes casos: artículo 426 referido a la facultad del Consejo a solicitar la constitución de garantía a los padres que ejercen patria potestad; artículo 427 referido a la petición del Consejo para que los padres rindan cuentas periódicas de su gestión; 467 referido a la designación que debe hacer el Consejo sobre el curador especial, que representará al incapaz en el juicio en que se promueva la suspensión de la patria potestad; 987 referido a la partición convencional en la que el incapaz resulte siendo copropietario de los bienes, en este caso el Consejo es citado para el pronunciamiento del Juez sobre la aprobación o no de esta partición convencional; 1307 referido a la transacción en la que de por medio haya intereses de un incapaz, aq̣uí el Juez aprueba la transacción escuchando al consejo de familia. En cuanto a las normas del Código Procesal Civil, el artículo 787 referido a la autorización para disponer derechos de incapaces, alude a la participación del consejo de familia como parte importante del proceso no contencioso.

\section{RECURSOS CONTRA LAS RESOLULCIONES DEL CONSEJO}

Se ha señalado que el Consejo de Familia es presidido por un Juez, el cual será el de familia si se trata de fiscalizar al tutor, o en su caso a los padres que ejerzan patria potestad, cuando la ley lo señale específicamente, y será el de 
Juez Paz Letrado, cuando el Consejo se forme para cautelar intereses de los incapaces mayores de edad; por lo tanto, las impugnaciones contra las resoluciones que adopte el Consejo se presentarán o ante el Juez de Familia, si se trata de acuerdos del consejo presidido por el Juez de Paz Letrado, o ante la Sala de Familia si se trata de acuerdos del Consejo presidido por un Juez de Familia. Veamos por separado estos recursos:

a) Consejo presidido por el Juez de Paz Letrado. Refiere el artículo 648 del Código Civil que de las resoluciones del Consejo presidido por el Juez de Paz, pueden apelar al Juez de primera instancia (hoy Juez especializado de Familia), cualquiera de los miembros que haya disentido de la mayoría al votarse el acuerdo; por ello, deciamos que para ejercer este derecho, las votaciones deben ser abiertas, única forma de viabilizar esta impugnación; el tutor o curador, sobre el particular creemos que sólo se estaría refiriendo al curador, pues si se trata de tutor, sabemos que el Juez que preside el Consejo es el de familia; también decimos, en su caso pueden interponer el recurso igualmente los padres del incapaz mayor de edad; cualquier pariente del menor que no esté integrando el consejo; y cualquier otro interesado en la decisión, el mismo que, decimos, debe demostrar legítimo interés económico o moral. En cuanto al plazo es de cinco días, salvo que se trate de resoluciones en que el Consejo declare la incapacidad de los curadores, acuerde su remoción o desestime su excusa, en cuyo caso el plazo es de 15 días.

b) Consejo presidido por el Juez de Familia. El artículo 649 refiere que de las resoluciones del consejo presidido por el Juez de menores (hoy Juez especializado en Familia), pueden apelar a la Sala Civil de la Corte Superior (hoy Sala de Familia) dentro del término de 5 días las personas indicadas en el párrafo precedente, o 15 días si se tratara de incapacidad, remoción o cuando se desestime la excusa de los tutores.

\section{RESPONSABILIDAD DE LOS MIEMBROS DEL CONSEJO}

Refiere el artículo 651 del Código Civil, que los miembros del Consejo de Familia son solidariamente responsables de los daños y perjuicios que, por dolo o culpa, sufra el sujeto a tutela o curatela, a no ser que hubiesen disentido del acuerdo que los causó, lo que implica que al no estar de acuerdo, salvaron su voto a través de las apelaciones que les franquea la ley. En efecto, si el Consejo se forma para cautelar y proteger intereses de incapaces que no 
pueden valerse por sí mismo, y por ello se les rcconoce como órgano de amparo del incapaz, resulta repudiable que se valgan de esa incapacidad, y terminen lesionando los intereses de aquel a quien debian cuidar, y por ello la ley les señala una responsabilidad que los llevaría a indemnizar al incapaz.

\section{RETARDO EN LA FORMACIÓN DEL CONSEJO DE FAMILIA}

Cuando las circunstancias lo ameriten, debe formarse el Consejo a la brevedad a fin de cautelar los intereses del incapaz; ahora bien, pueden suceder retardos u obstáculos que impidan la formación del consejo, y en atención a ello el legislador ha previsto fórmulas para superar estos inconvenientes. Veamos cuales son éstas:

a) Refiere el artículo 653 del Cọdigo Civil, que por falta o impedimento u omisión del Juez de Paz Letrado, en todo lo relativo a las atribuciones que por ley le corresponde respecto del Consejo de Familia, cualquiera de los parientes del incapaz o del ausente puede pedir al Juez de Familia, que el mismo desempeñe esas funciones o que designe al Juez de Paz Letrado que deba hacerlo. Obsérvese que ante una falta del Juez, el Consejo que debía formarse o reunirse no se hace, y por ello se faculta a los interesados a que soliciten que sea el Juez de Familia, el que instale o reúna al consejo de familia, sin perjuicio de la multa que se impone al juez negligente.

b) Esta misma facultad la tendrá la Sala de Familia, si se trata de que eÍ juez negligente es el de familia.

c) El artículo 654 del Código Civil faculta al Juez de Familia, o en su caso a la Sala de Familia, dictar en situación de urgencia, las providencias que favorezcan a las personas o intereses de los niños o adolescentes, mayores incapaces o ausentes, cuando haya retardo en la formación del Consejo u obstáculos que impidan su reunión o entorpezcan sus deliberaciones

\section{FIN DEL CARGO DE MIEMBRO DEL CONSEJO}

Es diferente el fin del cargo del consejo al fin del Consejo, y así el consejero cesará en el cargo sólo por causas previstas expresamente en la ley, todas ellas señaladas en el artículo 657 y que son:

1) Muerte del miembro del Consejo. 
2) Declaración de quiebra. En este caso por medida de previsión se aparta al consejero, que no ha sabido cuidar su propio patrimonio y en esa medida, según el legislador se vuelve incompetente para cuidar patrimonio ajeno.

3) Por remoción. En este caso las mismas causas que dan lugar a la remoción del tutor y del curador, se aplican para la remoción de los miembros, y en tal sentido es de aplicación el artículo 554 del Código Civil.

4) Por renuncia. Sólo en el caso de que le haya sobrevenido un impedimento legal para su desempeño.

\section{FIN DEL CONSEJO DE FAMILIA}

Se entiende que las razones que llevaron a la formación del Consejo han desaparecido, y por ello ya no tiene sentido que el consejo siga funcionando; sir embargo, habría que decir que este término no necesariamente cs definitivo, pues pueden reaparecer algunas circunstancias que justiuguen nuevamente la instalación y formación del Consejo. En efecto, refiere el artículo 658 del Código Civil, que el Consejo de Familia cesa en los mismos casos en que acaba la tutela o curatela, esto es por muerte del menor (en este caso el cese será definitivo), por llegar a su mayoría de edad, caso en el cual igualmente el cese es defintivo, por cesar $\stackrel{3}{a}$ incapacidad del menor en apilicación dè̃ átículo 46 del Código Civik, referido al matrimonio del adolescente de $t 6$ anos de edad, o por título oficial que lo habilite para ejercer: una profesión u oficio, caso en el cual igualmente el cese será definitivo por cesar la incapacidad del padre o madre conforme al articulo 580 del Código Civil; sin entuargo, si ese padre o madre vuelve a ser declarado interdicto. deberá nuevamente convocarse a un Consejo de Fam̌lia y por último termina el Consejo de Familia por reingresar el niño o adolescente bajo la patria potestad; sin embargo, pueden darse casos en que estando bajo patria potestad se requiera la formacion del Consejo, por ejemplo, cuando se presente oposición de intereses entre ellos, tal como lo refiere el artículo 460 del Código Civil. También termina el consejo refiriéndonos al mayor de edad incapaz, cuando éste fallezca o cuando se ha rehabilitađo.

\section{APRECIACIÓN FINAL}

No decimos nada nuevo cuando afirmamos que la familia está en crisis; sin embargo, lo que no se desea reconocer es que los factores que han 
lievado a la crisis familiar, no sólo se encuentran dentro del entorno famâilar, sino principalmente se dan desde fuera, esto es, factores externos que vienen de la misma sociedad, que exige a la familia el cumplimiento de su rol formativo y escuela de valores y principios, pero no crea las condiciones favorables para que esta familia pueda desarrollarse de la mejor manera, sino que al contrario, recibe la influencia negativa de los medios de conunicación social, con mensayes de violencia, la relativización de la autoriade materna y paterna sobre los hijos, el concepto equirvocado de la liberiad irrestricta respecto al matrimonio y su duración, las campañas abortivas y de esterilización, así como de los divorcios. Todo elio influye en la familia y se ve reflejada en las parejas conyugales desavenidas que al menor problema acuden al fácil expediente del divorcio, sin agotar el mínimo esfuerzo por encontrar soluciones. Este cuadro, entre otros efectos ha traido que el concepto de familia ampiliada, la de los padres e hijos y demás parientes, prácticamente no exista, y ahora tengamos como modelo de familia, la 11 amada nuclear, en donde sólo encontramos a los padres e hijos, y por cierto las familias monoparentales. Entonces, ¿cómo podría operar el Consejo de Fanilia, si es que esta institución descansa en la familia ampliada?, ya que precisamente son los parientes del incapaz los miembros natos de esta institución.

Por otro lado, del análisis de la regulación legal del Consejo de Familia hemos observado cómo esta instiłución que debe ser expeditiva, no termina siéndolo debido a la forma cómo ha sido regulado, en conde encontramos tha suerte de reglamento de la institución que llega al detalie, repitiendo en algunos casos supuestos innecesarios, pero sobre todo limitando su finalidad a proteger los intereses económicos de los incapaces, niños o adolescentes, o mayores de edad interdictados, sin detenerse a regular situaciones de los otros miembros de la familia que pueden estar atravesando diversos problemas derivados de conflictos netamente familiares. En esa circunstancia, el hoy llamado Consejo de Familia no tiene función que cumplir, lo que nos parece un error. Por otro lado, el Consejo de Familia no debe ser abordado sólo en el aspecto patrimonial, sino que igualrnente debe prestarse atención a los aspectos personales de los llamados a proteger; sobre el particular, recordar que el Consejo se forma para, entre otras cosas, vigilar al tutor, curador y excepcionalmente a los padres de familia; pues bien, todos estos guardadores no sólo tienen como una única misión, cuidar los intereses económicos, sino también y lo que es más importarite cuidar, la persona del incapaz sujeto al Consejo; sin embargo, la realidad nos muestra cómo la 
abundante pero innecesaria regulación tiene una fuerte carga de normas de contenido exclusivamente patrimonial, siendo pocas las normas referidas a la protección y guarda del incapaz.

Desde nuestra perspectiva la solución no pasa por la eliminación del Consejo de Familia, sino por una nueva regulación de la institución familiar, que responda a los fines que a lo largo del trabajo se han mencionado, y una ágil normatividad que haga expeditivo el funcionamiento de la misma. 


\section{REFERENCIAS}

Aguilar, Benjamín (2010) La fanilia en el Código Cizil Peruano. Lima: Ediciones legales.

Alvárez Caperochipi (1988) Curso de Derecho de Familia. Madrid: Civitas.

Belluscio, Augusto (1979) Derecho de familia. Buenos Aires: De Palma.

Borda, Guillermo (1988) Manual de Derecho de Familia. Buenos Aires: Abeledo Perrot.

Bossert Gustavo y Zanonni Eduardo (1999) Manual de Derecho de Familia. Buenos Aires: Astrea.

Pontificio Consejo para la Famulia-Santa Sede (1983) Carta de los Derechos de la Familia. Roma:Santa Sede.

Cornejo Chávez, Héctor (1998) Derecho Familiar Peruano. Lima: Gaceta Jurídica.

Gómez Piedrahita, Hernán (1992) Derecho de Familia. Bogotá: Temis.

Juan Pablo II (1981) Exhortación Apostólica Familiaris Consortio, Documento Vaticano. Lima: Ediciones Paulinas.

Kemelmayer de Carlucci (1998) El derecho de familia y los nuevos paradigmas. Buenos Aires: Rubinzal Culzoni.

Leguía, Guillermo (1935) "Manuel Lorenzo Vidaurre" Lima: La Voced'Italia.

Méndez Costa, María Josefa (1990) Derecho de Familia. Editores Santa Fe.

Montero Duhalt, Sara (1990) Derecho de Familia. Méjico: Porrúa.

Révora, Juan Carlos (1946) Instituciones de la Familia. Buenos Aires: Edit Guillermo Kraft Ltda.

Rodríguez Iturri, Roger (1998) Adolescencia, matrimonio y familia. Lima: Fondo Editorial de la Pontificia Universidad Católica del Perú.

Vega Mere, Yuri (2009) Las nuevas fronteras del Derecho de Familia. Lima: Motivensa Editora Jurídica. 